\title{
AdVANTAgES AND Limits OF FreE SPACE OPTICS
}

\author{
Sardar H. Ali \\ Computer Science Department, University of Zakho, \\ Kurdistan Region- Iraq
}

\begin{abstract}
Free space optics known as (FSO) is very popular now days this is because of increased demand for cheaper, faster and most important affordable internet. So many research scientists have taken the great interest in this field. FSO uses laser for transmitting data at the speed capable of reaching 2.5 Gbps through the air. And its systems use invisible infrared laser light wavelengths in the $780 \mathrm{~nm}$ to $1600 \mathrm{~nm}$ range. This article explains the FSO security, the transmission characteristics and also its challenges; although Free Space Optic systems can be a better solution for the needs of some broadband networking, there are limitations of bad climatic conditions that influence its performance such as fog, snow and too much rain can shut down the network. The performance of FSO is measured by Bit Error Rates (BER).
\end{abstract}

\section{KEYWORDS}

(FSO) Free Space optics, laser, transmission, Atmospheric turbulence and Scintillation.

\section{INTRODUCTION}

We are in a world that is rapidly relying on the technology. In the past years and for decades, fabulous expansion and development has been noticed in the field of different technologies such as communication and information. The increase of high speed has been used in videoconferencing, live streaming and also on the internet, the bandwidth of FSO is increasing hugely. Free Space Optics (FSO), known as optical wireless are systems of the telecommunication wireless that use free air from medium transmission to deliver optical data signals at highrates.Free Space Optics uses Light Amplification by Stimulated Emission of Radiation (LASER) and Light Emitting Diode (LED) for transmitting data, instead of closing off the data stream on all sides in a glass fiber; this data is broadcasting through the air at a range between $780 \mathrm{~nm}-1600 \mathrm{~nm}$ wavelengths. The use of these lasers is uncomplicated hypothesis which is similar to optical broadcasts using fiber-optic cables. The light goes through air more rapidly than the light in glass. That is the reason behind categorizing Free Space Optics as optical communications at the high speed as a light. These FSOs are already being used in different fields to communicate between submarines. Most of the fighter jets emit a lot of electromagnetic waves for the purpose of reducing the amount of electromagnetic waves jets. Different papers and studies show Free Space Optics data transmission through space. Advantges and its challenges are studied in their work.

In this paper, the performance of (FSOs) communication in the presence of atmospheric turbulence is presented. Factors that affect the performance of the communication channel in free space optical communication system is also presented inthe paper. In spite of the advantages of FSO, there are several challenges in a real-world deployment. Aerosol scattering, caused by the rain, snow and fog, leads to performance degradation. Another possible damage over FSO links is building-sway as a result of wind loads, thermal expansion and weak earthquakes and the key problem of SFO is that FSO links suffer from atmospheric turbulence because of scintillation, which leads to random amplitude fluctuations. This phenomenon, which is known as fading or scintillation, damages the link performance mostly for distances above $1 \mathrm{~km}$. 
International Journal of Advanced Smart Sensor Network Systems (IJASSN), Vol 9, No.1/2/3, July 2019 This paper is divided to different sections. The first section is the introduction and then the second section is how FSO works. The third section is FSO transmission. The fourth section shows the security of FSO and section fifth shows factors affecting FSO and the last Section presents our conclusions.

\section{How FSO WORKS}

Communication of Free space optics system functions as fixed Free Space Optical systems in other words the traditional. The technology is situated on the connection among Free Space Optics wireless units; each consists of an optical transceiver with a transmitter and a receiver to provide full-duplex capability (bi-directional). There is a fiber at the receiver side which turns the electrical signal to the optical signal in this end. A laser driver amplifies this electrical signal and provides enough current to drive the laser diode. Controlled light from the laser is heading for the receiver which focused their ray onto a silicon Avalanche photo Diode (APD). This APD changes the optical signal to an electrical one. After re-forming and some din filtering the electrical signal is turned back to the Optical signal. The maximum amount of data can be transferred at the speed of $2.5 \mathrm{Gbps}$.

In figure 1, the process of FSO system is clarified as an optical aerial used to emit the ray using Single Mode Fiber (SMF) termination to free space.At the receiver the optical beam is focused onto the fiber for detection. And amplify the beam signal if the climate is not good and this will be done by the Erbium Doped Feedback Amplifier (EDFA). Since fiber and free space optical broadcast links hold the same optical signal is capable of utilizing developed technologies and optical components developed for high bit rate fiber transmission. A free space broadcast is equal to the SMF broadcast assuming we omit atmospheric turbulence factor.
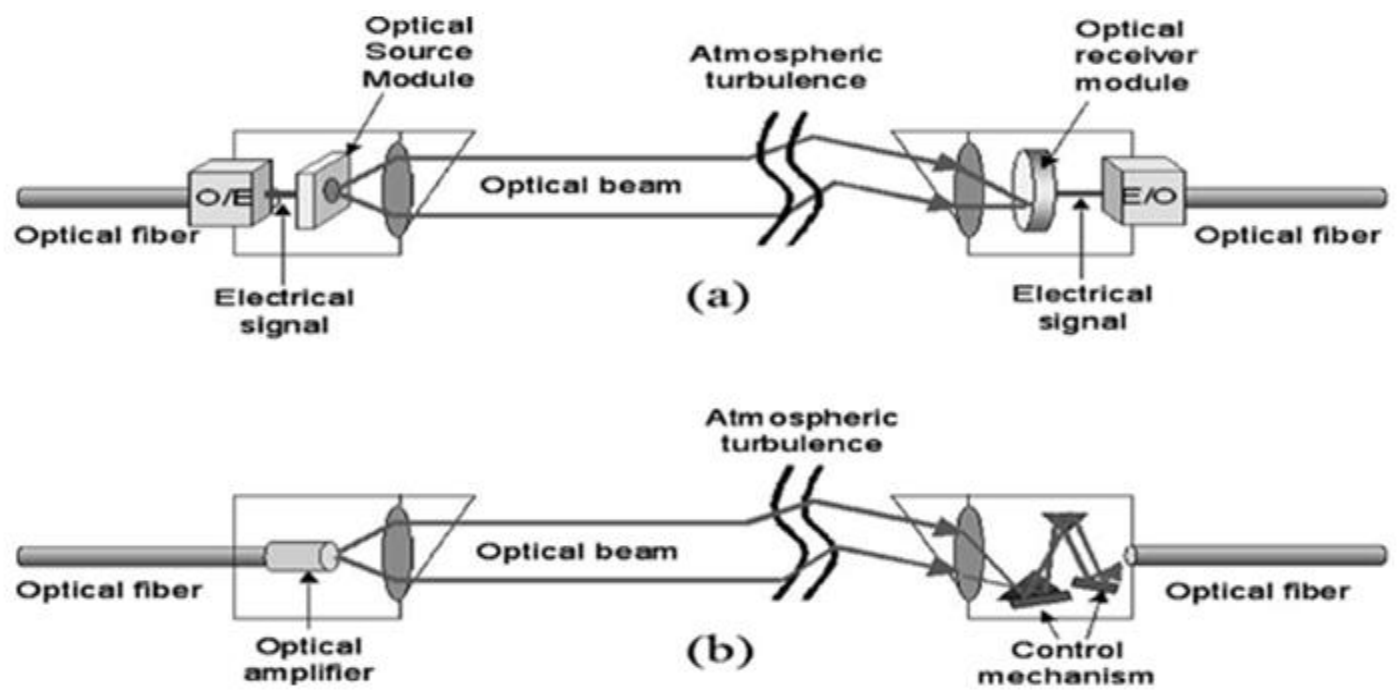

Figure 1: FSO system using (a) O/E and E/O conversion and (b) seamless connection of FSO beam and single mode fiber

Scientists propose that between orbiting satellites we should add FSO systems and combine with a single mode fiber (SMF). When an optical ray is broadcast the atmosphere requires a large aperture lens for the camera because of the large diameter at the receiver. The optical signal that is focused onto the fiber using the lens will be affected by turbulence as it goes through the atmosphere and vibrations at the installation site. The disadvantage of atmospheric turbulence 
International Journal of Advanced Smart Sensor Network Systems (IJASSN), Vol 9, No.1/2/3, July 2019 will bring about the reductions changes in the Angle of arrival (AOA) and in turn will lead to important variations in the power of light concentrated on the Single Mode Fiber (SMF).

\section{Transmission}

Laser also called light-emitting diode (LED), provides the broadcast optical signals and affects all the transmitter capabilities of the system. Detector sensitivity has a very important role in the entire system performance. For telecommunication reasons, lasers which are able to be modulated at $20 \mathrm{Mbps}$ to $2.5 \mathrm{Gbps}$ can meet current demands. In addition, how the device is modulated and how much modulated power is formed both are important to the selection of a device. With Lasers of two wavelength $(750 \mathrm{~nm}-850 \mathrm{~nm})$ and $(1550-1600 \mathrm{~nm})$, Free Space Optics systems have these characteristics:

-FSO operates for far distances at higher power levels

-Tiny path and low power utilization

-Works on a wide temperature range does not include main performance degradation.

-Finally, the mean time among breakdown that exceeds $10 \mathrm{yr}$.

\section{SeCURITy Of Free SPACE Optics}

The most important factor of transmitting data is security. FSO is much protected wireless system. Due to tight beam or beam confinement nature required for transmitting a signal, the laser beam cannot be detected by a spectrum of RF meter so it is one of FSO'S safe communications. The following are reasons behind FSO security:

-FSO laser beams cannot be detected with spectrum analyzers because of its security rather than other wirelesses.

-Laser transmissions travel alongside a line of sight path that cannot be encoded simply.

-Data can be broadcast over an encrypted connection adding to the degree of security that is available in FSO transmission networks.

-The beams of laser generated by Free Optics systematization are thin and imperceptible, making them more difficult to find and even harder to intercept and break.

\section{FACTORS AfFecting Free SPACE Optics}

As free space optics (FSO) has strong points, it also has some weak points that affect its actions when it transmits data these factors are as follows:

\subsection{Environmental Factors}

The FSO's link performance is mainly dependent on the climate of the location and the physical surroundings like buildings which can be obstacles. The weather is a key factor in the determining overall performance of an FSO link. An ordinary FSO system operates at a range that's twice or thrice that of the naked eye in any environment. Important factors affecting performance include atmospheric attenuation, scintillation, window attenuation, alignment or building motion, and solar interference. 


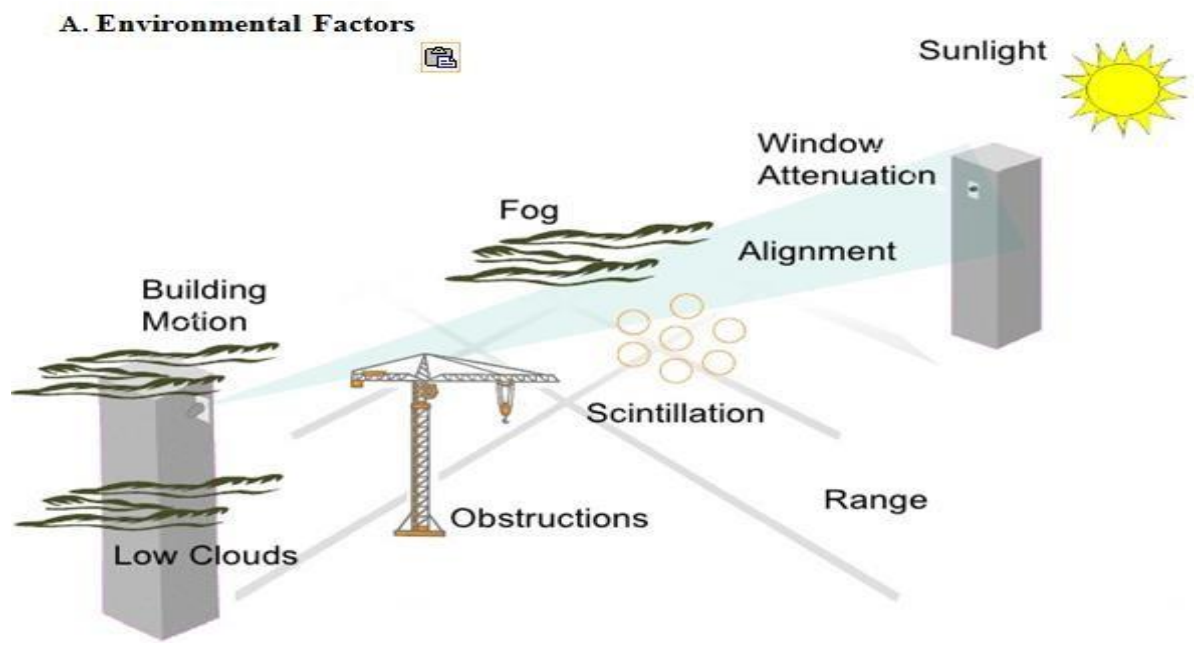

Figure 2: Environmental factors that affect FSO Transmission

The above figure explains the factors of demerits of FSO such as scintillation, low clouds, fog, atmospheric and window attenuation, and obstructions that affect FSO during its transmission. In the figure it is very clear how those stands onthe path of the transmission of FSO, for instance if we look at the low clouds, they stand as a straight obstacle for transmiting FSO.

\subsection{Atmospheric Attenuation}

Fog considers as the contributor for atmospheric attenuation because it results in absorption and scattering. Rain and snow have less impact on the Free Space Optics. The impact of fog on visibility as the distance goes on can be seen in the diagram in figure 3 this is a representation of some pictures taken on a foggy day in Denver, Colorado. The figure shows that it could bound the accessibility of FSO connection. In these cases, a high power laser with mitigation techniques assist to improve the probability of link availability. Commonly, $1550 \mathrm{~nm}$ lasers are favorite choice during deep reduction because of their high transmitted power.

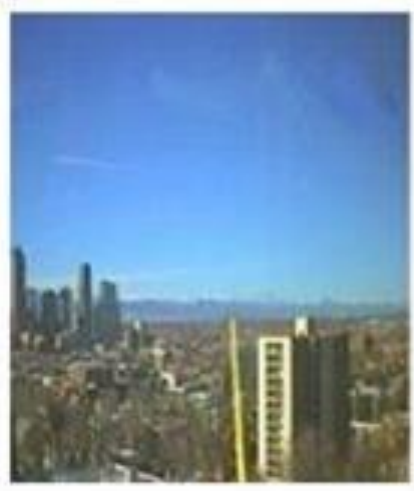

$6.5 \mathrm{~dB} / \mathrm{km}$

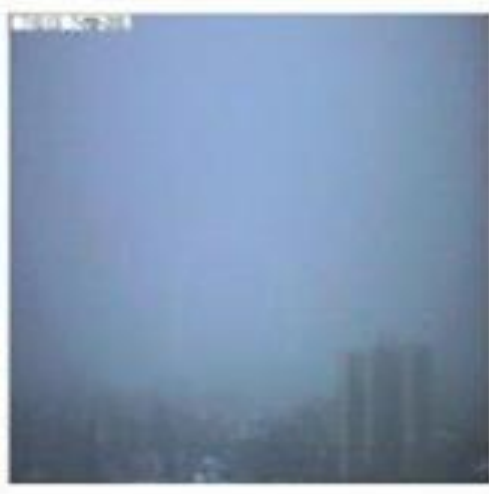

$150 \mathrm{~dB} / \mathrm{km}$

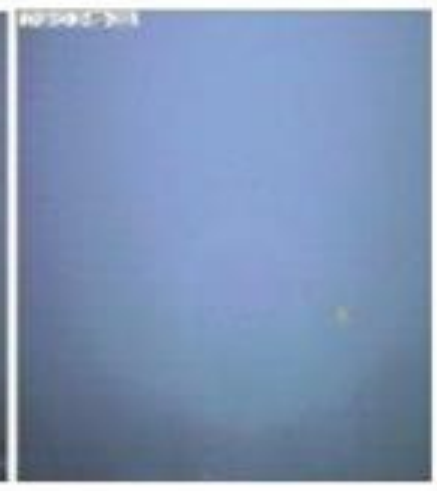

$225 \mathrm{~dB} / \mathrm{km}$

Figure 3: Fog event in Colorado, Denver 


\subsection{Scintillation}

Another challengingfactor that affect FSO is scintillation that is the change of light from bright light to dim light in a given period of time. The intensity of light changing is called atmospheric scintillation of a receiver that detects the signal from a transmitter. In other term, scintillation degrades Free Space Optics performance due to its temperature fluctuations of the signals received at the detector that is caused by variation in refractive indicator in transmitting path because of the temperature change. These indicators change because of the atmosphere to act like a series of small lenses that deflect portions of the light beam into and out of transmission path.

The time scale of these fluctuations is of the order of milliseconds, approximately equal to the time that it takes a volume of air the size of the beam to move across the path, and therefore is related to the wind speed. Scintillation can change by more than an order of magnitude during the course of a day, being the worst, or most scintillated, during midday when the temperature is the highest.

\section{ConClusion}

In summary the findings and performance of Free Space Optics are explained and summarized in this article based on its characteristics, data transmissions and applications. FSO enables optical transmission through the air at high rate. Even though Fee Space Optics communications were studied for many decades, and its networking is still in its first stage because of its challenges that faces such as environmental factors (bad weather) while passing data through the space (air). Recent studies showed these factors and challenges of the weather and different studies are in process concerning this viewpoint to reduce the attenuation effects by presenting new system design like WDM -FSO, OFDM -FSO system. As a result new techniques can be designed by combination of these designs and by enhancing these techniques, system designing can be improved and the disadvantages of FSO system can be reduced to thelowest level.

\section{REFERENCES}

[1] B. L. Edwards, "NASAs current activities in free space optical communications," in International Conference on Space Optics, vol. 7, 2014, p. 10

[2] D. Messier, "DLR Researchers Set World Record in Freespace Optical Communications," Nov. 2016, [online]. Available: http://www.parabolicarc.com/2016/11/05/

[3] F. Marioni, Z. Sodnik, and F.E. Zocchi, "2.5-Gb/s free-space optics link over $1.1 \mathrm{~km}$ with direct fiber coupling to commercial devices,"in Free-Space Laser Communications IV, vol.5550, pp.6069, Oct. 2004.

[4] Free - Space Optical Alliance.http:// www. wcai.com/ fsoalliance

[5] G. Nykolak, P.F. Szajowski, D. Romain, G.E. Tourgee, H.M. Presby,

[6] H. A. Fadhil, A. Amphawan, H. A. B. Shamsuddin et al., "Optimization of free space optics parameters: an optimum solution for bad weather conditions," Optik, vol. 124, no. 19, pp. 39693973, 2013.

[7] H.Willebrand and B. Ghuman, Free Space Optics: Enabling Optical Connectivity in Today's Networks, Sams Publishing, 2002.

[8] I.I. Kim, M. Mitchel, and E. Korevaar, "Measurement of scintillation for free-space laser communication at $785 \mathrm{~nm}$ and $1550 \mathrm{~nm}$," Optical Wireless Communications II, ed. E.J. Korevaar, 
International Journal of Advanced Smart Sensor Network Systems (IJASSN), Vol 9, No.1/2/3, July 2019 vol.3850, pp.49-62, SPIE, Sept. 1999.

[9] Infrared Communication Systems Association. http://www.icsa.org.

[10] J. C. Juarez, A. Dwivedi, A. R. Mammons, S. D. Jones, V.Weerackody and R. A. Nichols, "Freespace optical communicationsfor next-generation military networks," Communications Magazine,IEEE, vol. 44, 2006, pp. 46- 51.

[11] K. Amarjeet and P.R Kumar "Analysis the effect Atmosphere Turbulence in Free-Space Optical (FSO) Communication Systems," International Journal of Engineering and Innovative Technology (IJEIT) Volume 3, Issue 11, May 2014.

[12] L.C. Andrews, R.L. Phillips, C.Y. Hopen, Laser Beam Scintillation with Applications, SPIE Publications, 2001.

[13] M. A. Khalighi and M. Uysal, "Survey on free space optical communication: A communication theory perspective," IEEE Comm. Surve. \&Tut., vol. 16, no. 4, pp. 2231-2258, 2014.

[14] M. Abtahi, P. Lemieux, W. Mathlouthi, L.A. RuschSuppression of turbulence-induced scintillation in free-space optical communication systems using saturated optical amplifiers IEEE/OSA J. Light. Technol., 24 (December (12)) (2006) (4996-4973)

[15] M. Taheri, N. Ansari, J. Feng, R. Rojas-Cessa, and M. Zhou, "Provisioning Internet access using FSO in high-speed rail networks," IEEE Network, vol. 31, no. 4, pp. 96-101, 2017.

[16] R. N. Mahalati and J. M. Kahn, "Effect of fog on free-space optical links employing imaging receivers," Opt. Exp., vol. 20, no. 2, pp. 1649-661, 2012.

[17] S. A. Al-Gailani, A. B. Mohammad, and R. Q. Shaddad, "Enhancement of free space optical link in heavy rain attenuation using multiple beam concept," Optik, vol. 124, no. 21, pp. 4798-4801, 2013.

[18] S. Photonics. Nexus free-space optical communications system. Last Access: 5/26/2017. [Online] Available: http://www.saphotonics.com/wp-content/uploads/2017/02/Nexus-Datasheet.pdf

[19] Z. Suriza, I.M. Rafiqul, A. K. Wajdi, andA.W.Naji, "Effects of rain intensity variation on rain attenuation prediction for Free Space Optics (FSO) links," in Proceedings of the International Conference on Computer and Communication Engineering (ICCCE '12), pp. 680-685, IEEE, Kuala Lumpur, Malaysia, July 2012.

[20] R. Liao, "Fading pdf of free-space optical communication system with pointing error," Ph.D.dissertation,2011.[Online].Available:

http://digitalcommons.mtu.edu/cgi/viewcontent.cgi?article= $1063 \&$ context=etds 